\title{
Comparison of proliferating cell nuclear antigen expression in odontogenic keratocyst and ameloblastoma: an immunohistochemical study
}

\author{
Hiroshi Takahashi ${ }^{\text {a,*}}$, Shuichi Fujita ${ }^{\text {a }}$, Shigeru Yamabe ${ }^{\mathrm{b}}$, Takeshi Moriishi ${ }^{\mathrm{a}}$, Haruo Okabe ${ }^{\mathrm{a}}$, \\ Yoshifumi Tajima ${ }^{\mathrm{c}}$ and Akio Mizuno ${ }^{\mathrm{b}}$ \\ ${ }^{a}$ Department of Oral Pathology, Nagasaki University School of Dentistry, 1-7-1 Sakamoto, \\ Nagasaki 852-8588, Japan \\ ${ }^{\mathrm{b}}$ First Department of Oral and Maxillofacial Surgery, Nagasaki University School of Dentistry, \\ Nagasaki, Japan \\ ${ }^{\mathrm{c}}$ Department of Oral Pathology, Meikai University School of Dentistry, Sakado, Saitama, Japan
}

Received 12 May 1997

Revised 26 February 1998

Accepted 26 February 1998

\begin{abstract}
Proliferating cell nuclear antigen (PCNA) is a nuclear protein synthesized in the late G1 and S phase of the cell cycle, and immunohistochemical detection of the protein represents a useful marker for the proliferating fraction of cells in tissue specimens. PCNA expression was studied in odontogenic keratocysts $(n=15)$ and ameloblastomas $(n=46)$ using an avidin-biotin-peroxidase complex method on routinely processed paraffin sections. The percentage of PCNA-positive cells determined by point counting was significantly lower in the ameloblastomas (mean 9.4\%, standard deviation (SD) 11.0) than in odontogenic keratocysts (mean 29.9\%, SD 24.0). In ameloblastomas, the mean percentage of PCNA-positive cells was lowest in the acanthomatous pattern and highest in plexiform pattern. The mean percentage of PCNA-positive cells in plexiform pattern was non-significantly higher than that in follicular pattern. The mean percentage of PCNA-positive cells in plexiform and follicular patterns was significantly higher than that in cyctic and acanthomatous patterns. The frequency of PCNA-positive cells was significantly higher in the peripheral cells of follicular and plexiform patterns than in the central cells of both patterns $(p<0.01)$. Therefore, peripheral cells were regarded as reserve cell of central cells. The mean percentage of PCNA-positive cells in the epithelial lining of odontogenic keratocyst was not significantly different from those in the peripheral cells of follicular and plexiform patterns of ameloblastoma. In contrast, the odontogenic keratocyst exhibited a mean percentage of PCNA-positive cells which was statistically higher than that in other histological elements of ameloblastomas. The present study suggests that odontogenic keratocyst is regarded as benign odontogenic tumour.
\end{abstract}

Keywords: Ameloblastoma, immunohistochemistry, odontogenic keratocyst, proliferating cell nuclear antigen

\section{Introduction}

Ameloblastomas are rare epithelial tumours of presumed odontogenic origin, constituting between 11 and $18 \%$ of all odontogenic tumours [3,21]. Although mostly benign neoplasms of the central jaw bones,

\footnotetext{
*Corresponding author: Hiroshi Takahashi, Dr. Med. Sci., Associate Professor, Department of Oral Pathology, Nagasaki University School of Dentistry, 1-7-1 Sakamoto, Nagasaki 852-8588, Japan.
} 
they often show a destructive and recurrent behaviour [8]. A wide spectrum of histological patterns have been described for ameloblastoma [11]. These variations include follicular, plexiform, acanthomatous, granular cell, basal cell, unicystic, desmoplastic, and malignant types. Histologically ameloblastoma epithelium resembles that of the enamel organ of the developing tooth. The peripherally located tall columnar cells in the tumour follicles resemble developing ameloblasts of the tooth germ and the centrally located cells those of stellate reticulum.

Odontogenic keratocysts are thought to derive from the enamel organ or from the dental lamina $[1,14$, 32]. Clinically, there are similarities with the ameloblastoma as to the age of the patient, the localization of the lesion, the radiographic picture, and the tendency for recurrence [22]. Odontogenic keratocysts are characterized by a high rate of recurrence $[2,5,6,22,25]$, which has been estimated to be between 6 and $60 \%[6,33]$. For the explanation of this recurrence, several papers investigating cell kinetics in the epithelial linings of odontogenic cysts have been reported using a variety of methods including mitotic activity [4,15], tritiated thymidine uptake [28] and immunocytochemistry on cryostat sections [16]. These observations, together with recent studies showing high levels of p53 expression [20] and high number of proliferating cell nuclear antigen positive cells $[12,13]$ indicated that the epithelial lining of odontogenic keratocysts may have some intrinsic growth potential not present in other odontogenic cyst linings. Indeed, it has been suggested that odontogenic keratocysts might be regarded as benign neoplasms [23].

An understanding of the behaviour of odontogenic keratocyst and ameloblastoma is warranted due to their destructive clinical behaviour. The utilization of new immunohistochemical techniques is valuable in proving additional characterization of the tissue components of these lesions.

Proliferating cell nuclear antigen (PCNA) is a $36 \mathrm{kD}$ nuclear protein, synthesized in late $\mathrm{G} 1$ and $\mathrm{S}$ phases of the cell cycle, whose expression is associated with DNA synthesis and cell proliferation [18,31]. According to recent molecular biologic studies, PCNA is an essential protein for DNA replication, regulating the cell cycle [30]. PCNA reflects dysregulation of proliferative activity and/or some of the genetic changes. Therefore, PCNA expression has been generally used as a useful indicator to determine the biologic behaviour of various lesions $[17,19]$. PCNA staining could be assessed from formaldehyde treated paraffin embedded histologic specimens using monoclonal antibody PC10 [7,9]. PCNA has the advantage of preservation of the histologic constitution. If a cell population is in the high proliferative state, the sites of dysregulation of cell proliferation could be detected using immunohistochemical staining of PCNA.

Currently, few data exist on the occurrence of PCNA in odontogenic lesions $[10,12,13]$. The aim of the present study was to compare the frequency of PCNA-positive cells between odontogenic keratocyst and ameloblastoma. Additionally, we estimated the frequency of PCNA-positive cells among the histological and cellular elements of ameloblastomas.

\section{Materials and methods}

\subsection{Tissues}

Fifteen odontogenic keratocysts and 46 ameloblastomas were retrieved from the files of the Department of Oral Pathology, Nagasaki University School of Dentistry, and the Department of Pathology, Nagasaki University Hospital. 


\subsection{Histopathologic examination}

All resected specimens were fixed in $10 \%$ formaldehyde solution for 18-48 $\mathrm{h}$ and embedded in paraffin. Each slice containing the lesion was cut to $3 \mu \mathrm{m}$ in thickness and stained with hematoxylin and eosin and reviewed in detail microscopically. The histologic diagnosis of odontogenic keratocysts and ameloblastomas was classified according to the criteria defined by the 1992 World Health Organization's International Histological Classification of Tumours [11].

\subsection{Immunohistochemical PCNA staining}

To investigate the cell proliferative state of odontogenic lesions, a mouse monoclonal antibody against PCNA (PC10, Dako Japan, Kyoto, Japan) was used for immunohistochemical staining of paraffin sections. Immunohistochemical staining was performed using the avidin-biotin-peroxidase complex (ABC) method. Sections were cut at $3 \mu \mathrm{m}$, mounted on poly-L-lysine-coated glass slides, and air dried overnight at $37^{\circ} \mathrm{C}$. They were deparaffinized through xylene and graded alcohols and treated for 10 min with methanol and $0.5 \%$ hydrogen peroxide to block endogenous peroxidase activity. The sections then were washed in phosphate-buffered saline (PBS), and normal horse serum was applied for 20 min to reduce non-specific antibody binding. PCNA staining was performed with a monoclonal mouse anti-PCNA antibody, PC10 (DAKO). PC10 diluted to $1: 75$ was incubated overnight at $4{ }^{\circ} \mathrm{C}$ in a moist chamber. Sections were washed extensively and incubated with biotinylated horse antimouse immunoglobulin $\mathrm{G}$ for $30 \mathrm{~min}$. Subsequent incubation with avidin-biotin-peroxidase complex reagent (Vector Laboratories, Burlingame, CA) was performed for 30 min after extensive washing with PBS. Diaminobenzidinehydrogen peroxide (Sigma Chemical Co., St. Louis, MO) was used as chromogen, and methyl green counterstaining was added. Positive controls always included sections of human tonsil stained with and without the primary antibody. For negative controls, PCNA antibody was replaced with fetal calf serum in Tris- $\mathrm{HCl}$ buffer.

\subsection{Immunohistochemical assessment}

To estimate cell proliferative activity of the odontogenic keratocysts and ameloblastomas, at least 10 representative areas, each containing over 100 cyst-lining cells or tumour cells, were observed under high-power field $(\times 40$ objective and $\times 10$ oculars $)$ from the most evenly and heavily labelled areas. All positive cells were counted regardless of intensity of staining. A minimum of 1000 lesional cells were counted in each section, using a graticule to prevent duplicate counting. The percentage of PCNA positivity stained lesional cells was calculated. Statistical significance was assessed by the Student's $t$-test and a $p$ value of $<0.05$ was considered to be significant.

\section{Results}

\subsection{Histology of odontogenic keratocyst and ameloblastoma}

Histological examination of the odontogenic keratocysts showed palisading of the basal cell layer with nuclear polarization and a corrugated keratinized layer with alternating areas of orthokeratosis and parakeratosis. Variable amounts of keratin were seen in the cystic lumen. The PCNA-positive cells were evaluated in the basal, suprabasal and spinous layers of the cystic process. The histological patterns 
Table 1

PCNA-positive cells in ameloblastoma and odontogenic keratocyst

\begin{tabular}{|c|c|c|c|}
\hline $\begin{array}{l}\text { Histological type } \\
\text { and cell type }\end{array}$ & $\begin{array}{c}\text { Number of } \\
\text { cases }\end{array}$ & Mean \pm SD $(\%)$ & Range (\%) \\
\hline Ameloblastoma & 46 & $9.4 \pm 11.0 \square^{5}$ & $0-42.4$ \\
\hline Follicular pattern & 37 & $10.4 \pm 10.8 \frac{6}{6}$ & $1.8-40.1$ \\
\hline peripheral cell & 37 & $17.1 \pm 11.91$ & $3.6-40.1$ \\
\hline central cell & 37 & $9--3.8 \pm 2.7={ }^{7}$ & $1.8-7.9$ \\
\hline Plexiform pattern & 25 & $10-\left\ulcorner 15.6 \pm 12.6 \frac{3}{\Gamma}\right.$ & $0.9-42.4$ \\
\hline peripheral cell & 25 & : $23.1 \pm 12.42$ & $4.2-42.4$ \\
\hline central cell & 25 & L $-8.1 \pm 7.7=$ & $0.9-20.5$ \\
\hline Cystic pattern & 30 & $4.9 \pm 3.5 \overline{\overline{7}}$ & $0.9-9.0$ \\
\hline Acanthomatous pattern & 17 & 0 & 0 \\
\hline Odontogenic keratocyst & 15 & $\llcorner-29.9 \pm 24.0 \leqq$ & $6.8-61.8$ \\
\hline
\end{tabular}

of ameloblastoma observed in this study comprised the follicular, plexiform, cystic and acanthomatous patterns. Two or more histological patterns were frequently observed in the same patient. They were distributed as follows: follicular pattern, $n=37$; plexiform pattern, $n=25$; cystic pattern, $n=30$; and acanthomatous pattern, $n=17$. Tumour cells in the follicular and plexiform patterns were comprised of peripheral tall columnar cells and central stellate cells.

\subsection{Comparison of the PCNA-positive cells among ameloblastoma cases}

Results are summarized in Table 1. Among the histological patterns of ameloblastoma, the mean percentage of PCNA-positive cells was highest in plexiform pattern (Fig. 1) and PCNA-positive cells were not found in the keratinized cells and metaplastic squamous cells of acanthomatous pattern (Fig. 2). In plexiform pattern, there was a non-significant increase of mean percentage of PCNA-positive cells compared with that of follicular pattern (Fig. 3). The mean percentage of PCNA-positive cells in the peripheral cells of follicular and plexiform patterns was significantly higher than that of central cells in follicular and plexiform patterns, respectively $(p<0.01)$. The statistically significant difference was observed in the mean percentage of PCNA-positive cells between epithelial lining cells in cystic pattern (Fig. 4) and neoplastic cells in follicular and plexiform patterns $(p<0.01)$.

\subsection{Comparison of the PCNA-positive cells between odontogenic keratocysts and ameloblastomas}

The mean percentage of PCNA-positive cells in the epithelial linings of odontogenic keratocysts (Fig. 5) was significantly higher than that in ameloblastomas $(p<0.01)$. The mean percentage of PCNApositive cells in the odontogenic keratocysts was higher than that in the peripheral cells of follicular and plexiform patterns, but none of the differences reached a statistically significant level. The odontogenic keratocysts exhibited a mean percentage of PCNA-positive cells which was statistically higher than those in the central cells of follicular and plexiform patterns and in the epithelial linings of cystic ameloblastomas $(p<0.01)$. 


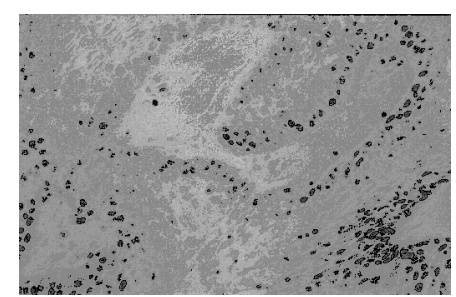

Fig. 1. PCNA expression in plexiform pattern of ameloblastoma. Positive nuclei for PC10 are less numerous in the central areas than in the peripheral layer. ABC method with methyl green counterstain, $\times 50$.

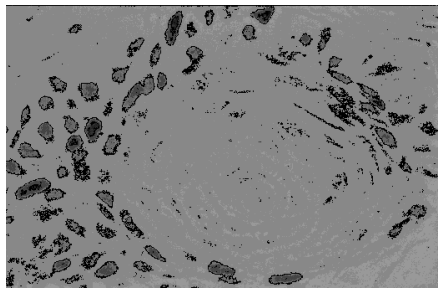

Fig. 2. PCNA expression in acanthomatous pattern of ameloblastoma. Positive nuclei for PC10 are not observed in the metaplastic squamous cells within the islands of follicular pattern. Some nuclei of peripheral cells in the follicular pattern which surrounds the area of acanthomatous pattern are positive for PC10. ABC method with methyl green counterstain, $\times 200$.

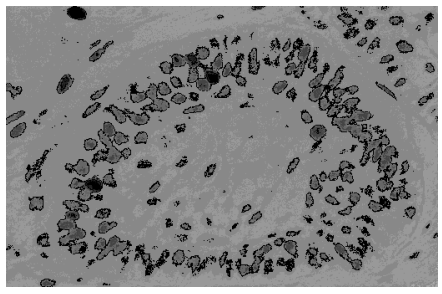

Fig. 3. PCNA expression in follicular pattern of ameloblastoma. Positive nuclei for PC10 are predominantly found in the peripheral cells. Some nuclei of central cells are positive for PC10. ABC method with methyl green counterstain, $\times 135$.

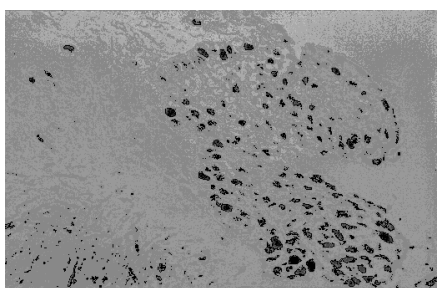

Fig. 4. PCNA expression in cystic pattern of ameloblastoma. Cystic tumour lining shows some tumour cell nuclei with positive results for $\mathrm{PC} 10$. ABC method with methyl green counterstain, $\times 132$.

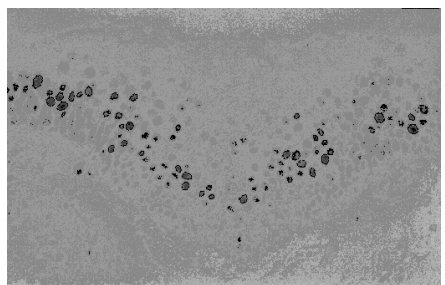

Fig. 5. PCNA expression in odontogenic keratocyst. Cystic epithelial lining shows a predominantly suprabasal cell labelling pattern. ABC method with methyl green counterstain, $\times 100$. 


\section{Discussion}

We have retrospectively investigated cell proliferation in odontogenic keratocyst and ameloblastoma, using PCNA immunohistochemistry. PCNA is a nuclear protein that is synthesized in advanced G1 and $\mathrm{S}$ phases of the cell cycle and is, therefore, correlated with the cell proliferative state [31]. Cell kinetic information has been shown to be an important factor in histologically based tumour classifications and also in the assessment of prognosis of malignant tumours $[7,29]$. In the previous studies, a linear correlation between the percentage of PCNA-positive cells and S $+\mathrm{G} 2+\mathrm{M}$ or S phase fraction measured by flow cytometry was recorded [9,31]. Also found was a linear correlation between the percentages of PCNA-positive cells and BrdU-labelled cells [27]. These findings suggest that PCNA immunostaining may be used as a marker of cell proliferation in various tumours.

To our knowledge, few data exist on the comparative study of occurrence of PCNA-positive cells in the odontogenic keratocyst and ameloblastoma. The results of the present study, using clone PC10 on routinely fixed and processed tissues, demonstrate that epithelial linings of odontogenic keratocysts contain significantly higher numbers of PCNA-positive cells than the neoplastic cells of ameloblastomas. These results suggest greater proliferative activity in epithelial linings of odontogenic keratocysts, in accord with their more aggressive clinical behaviour. The higher number of PCNA-positive cells detected in odontogenic keratocysts is consistent with data from previous studies using mitotic counting, tritiated thymidine incorporation, and Ki67 and PCNA immunostaining methods [4,12,15,16,24,28]. This, together with the known growth characteristics of odontogenic keratocyst in vitro [26,28] and in vivo [23], suggests that much of the PCNA detected in the epithelial linings of odontogenic keratocysts is associated with cell cycle-related DNA synthesis.

The distribution of PCNA-positive cells within epithelial linings of odontogenic keratocysts located predominantly in suprabasal layers. This pattern of PCNA expression is consistent with previous studies showing a predominant suprabasal distribution of tritiated thymidine incorporation, mitotic activity and Ki67 immunostaining within epithelial linings of odontogenic keratocyst $[4,16,28]$. Ameloblastoma and odontogenic keratocyst have some clinical features in common, such as location, age and degree of aggressiveness. These entities are derived from the same cell lineage and some histologic similarities are also present, including columnar basal cells with palisading and reverse polarization of their nuclei. The present study may support the theory by Shear [23] who suggested that odontogenic keratocysts may be regarded as benign odontogenic neoplasm. This could result in a significantly higher PCNA-positive cells in odontogenic keratocyst than that in ameloblastoma.

To date, data on the presence of PCNA-positive cells in ameloblastomas are scarce, with only two reports on this topic in the literature [10,13]. More recently, Li et al. [13] reported that PCNA labelling index of solid ameloblastomas of follicular type was significantly higher than those of different epithelial components (cystic tumour lining, intraluminal nodules and invading islands) in unicystic ameloblastoma. This finding agrees well with the data obtained in the present study. Kim and Yook [10] demonstrated that there was no difference among the proliferating activities in the different histological types of solid ameloblastomas, such as follicular, plexiform, acanthomatous, basal cell and granular cell types. On the contrary, acanthomatous pattern in our investigation showed no immunoreactivity for PCNA. This discrepancy of PCNA labelling index in acanthomatous pattern between the investigation of Kim and Yook [10] and the present study may be explained by the different histological criteria of acanthomatous pattern. We strictly regarded only the area of keratinized and metaplastic squamous cells as an acanthomatous pattern. Interestingly, the present study indicated that the PCNA labelled cells in peripheral cells of follicular and plexiform patterns are significantly higher than those in central cells of 
both patterns. Thus the predominant distribution of PCNA-positive cells in peripheral cells of follicular and plexiform patterns could be regarded as reserve cell with proliferative activity in ameloblastoma.

\section{References}

[1] M. Altini and M. Cohen, The follicular primordial cyst-odontogenic keratocyst, Int. J. Oral Surg. 2 (1982), 175-182.

[2] G. Anneroth and L.S. Hansen, Variations in keratinizing odontogenic cysts and tumours, Oral Surg. 54 (1982), 530-546.

[3] S.N. Bhaskar, Oral pathology in the dental office: Survey of 20,575 biopsy specimens, J. Am. Dental Assoc. 76 (1968), 761-766.

[4] R.M. Browne, The odontogenic keratocyst. Histological features and their correlation with clinical behaviour, Br. Dent. J. 131 (1971), 249-259.

[5] R. Chuong, R.B. Donoff and W. Guralnick, The odontogenic keratocyst, J. Oral Maxillofac. Surg. 40 (1982), $797-802$.

[6] O. Donatsky and E. Hjørting-Hansen, Recurrence of the odontogenic keratocyst in 13 patients with the nevoid basal cell carcinoma syndrome. A 6-year follow-up, Int. J. Oral Surg. 9 (1980), 173-179.

[7] R.L. Garcia, M.D. Coltrera and A.M. Gown, Analysis of proliferative grade using anti-PCNA/Cyclin monoclonal antibodies in fixed, embedded tissue. Comparison with flow cytometric analysis, Am. J. Pathol. 134 (1989), 733-739.

[8] D.G. Gardner and A.M.J. Pecak, The treatment of ameloblastoma based on pathologic and anatomic principles, Cancer 46 (1980), 2514-2519.

[9] P.A. Hall, D.A. Levison, A.L. Woods, C.C.-W. Yu, D.B. Kellock, J.A. Watkins, D.M. Barnes, C.E. Gillett, R. Camplejohn, R. Dover, N.H. Waseem and D.P. Lane, Proliferating cell nuclear antigen (PCNA) immunolocalization in paraffin sections: an index of cell proliferation with evidence of deregulated expression in some neoplasms, J. Pathol. 162 (1990), $285-294$.

[10] J. Kim and J.I. Yook, Immunohistochemical study on proliferating cell nuclear antigen expression in ameloblastomas, Oral Oncol. Eur. J. Cancer 30B (1994), 126-131.

[11] I.R.H. Kramer, J.J. Pindborg and M. Shear, Histological Typing of Odontogenic Tumours. International Histological Classification of Tumours, 2nd edn, WHO, Geneva, 1992.

[12] T.-J. Li, R.M. Browne and J.B. Matthews, Quantification of $\mathrm{PCNA}^{+}$cells within odontogenic jaw cyst epithelium, J. Oral Pathol. Med. 23 (1994), 184-189.

[13] T.-J. Li, R.M. Browne and J.B. Matthews, Expression of proliferating cell nuclear antigen (PCNA) and Ki-67 in unicystic ameloblastoma, Histopathology 26 (1995), 219-228.

[14] R.B. Lucas, Pathology of Tumours of the Oral Tissues, 3rd edn, Churchill Livingstone, Edinburgh, 1976.

[15] D.M.G. Main, The enlargement of epithelial jaw cysts, Odont. Rev. 21 (1970), 29-49.

[16] J.B. Matthews, G.I. Mason and R.M. Browne, Epithelial cell markers and proliferating cells in odontogenic jaw cysts, J. Pathol. 156 (1988), 283-290.

[17] A. Mayer, M. Takimoto, E. Fritz, G. Schellander, K. Kofler and H. Ludwig, The prognostic significance of proliferating cell nuclear antigen, epidermal growth factor receptor, and MDR gene expression in colorectal cancer, Cancer 71 (1993), 2454-2460.

[18] K. Miyachi, M.J. Fritzler and E.M. Tan, Autoantibody to a nuclear antigen in proliferating cells, J. Immunol. 121 (1978), $2228-2234$.

[19] I.O.L. Ng, E.C.S. Lai, S.T. Fan, M. Ng, A.S.Y. Chan and M.K.P. So, Prognostic significance of proliferating cell nuclear antigen expression in hepatocellular carcinoma, Cancer 73 (1994), 2268-2274.

[20] G.R. Ogden, D.M. Chisholm, R.A. Kiddie and D.P. Lane, p53 protein in odontogenic cysts: increased expression in some odontogenic keratocysts, J. Clin. Pathol. 45 (1992), 1007-1010.

[21] J.A. Regezi, D.A. Kerr and R.M. Courtney, Odontogenic tumours: analysis of 706 cases, J. Oral Surg. 36 (1978), 771-778.

[22] W.G. Shafer, M.K. Hine and B.M. Levy, A Textbook of Oral Pathology, 3rd edn, W.B. Saunders, Philadelphia, 1974.

[23] M. Shear, Cysts of the jaws: recent advances, J. Oral Pathol. 14 (1985), 43-59.

[24] P.J. Slootwag, p53 protein and Ki-67 reactivity in epithelial odontogenic lesions. An immunohistochemical study, J. Oral Pathol. Med. 24 (1995), 393-397.

[25] K. Sombatpium and J.K. Petersen, Nevoid basal cell carcinoma syndrome: conservative dental treatment, Int. J. Oral Surg. 9 (1980), 404-407.

[26] G. Stenman, B. Magnusson, B. Lennartsson and M. Juberg-Ode, In vitro growth characteristics of human odontogenic keratocysts and dentigerous cysts, J. Oral Pathol. 15 (1986), 143-150.

[27] M.M. Tinnemans, M.H. Lenders, G.P. ten Velde, S.S. Wagenaar, G.H. Blijham, F.C. Ramaekers and B. Schutte, Evaluation of proliferation parameters in in vivo bromodeoxyuridine labelled lung cancers, Virchows Arch. A: Anat. Pathol. 427 (1995), 295-301.

[28] P.A. Toller, Autoradiography of explants from odontogenic cysts, Br. Dent. J. 131 (1971), 57-61.

[29] T. Visakorpi, Proliferative activity determined by DNA flow cytometry and proliferating cell nuclear antigen (PCNA) immunohistochemistry as a prognostic factor in prostatic carcinoma, J. Pathol. 168 (1992), 7-13. 
[30] S. Waga, G.J. Hannon, D. Beach and B. Stillman, The p21 inhibitor of cyclin-dependent kinases controls DNA replication by interaction with PCNA, Nature 369 (1994), 574-578.

[31] A.L. Woods, P.A. Hall, N.A. Shepherd, A.M. Hanby, N.H. Waseem, D.P. Lane and D.A. Levison, The assessment of proliferating cell nuclear antigen (PCNA) immunostaining in primary gastrointestinal lymphomas and its relationship to histological grade, $\mathrm{S}+\mathrm{G} 2+\mathrm{M}$ phase fraction (flow cytometric analysis) and prognosis, Histopathology 19 (1991), 21-27.

[32] J.M. Wright, The odontogenic keratocyst: orthokeratinized variant, Oral Surg. 51 (1981), 609-618.

[33] N. Zachariades, S. Papanicolaou and D. Triantafyllou, Odontogenic keratocysts: review of the literature and report of sixteen cases, J. Oral Maxillofac. Surg. 43 (1985), 177-182. 


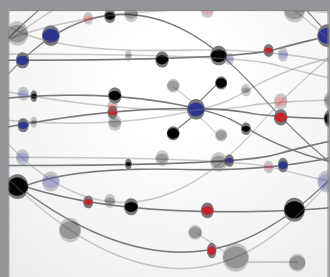

The Scientific World Journal
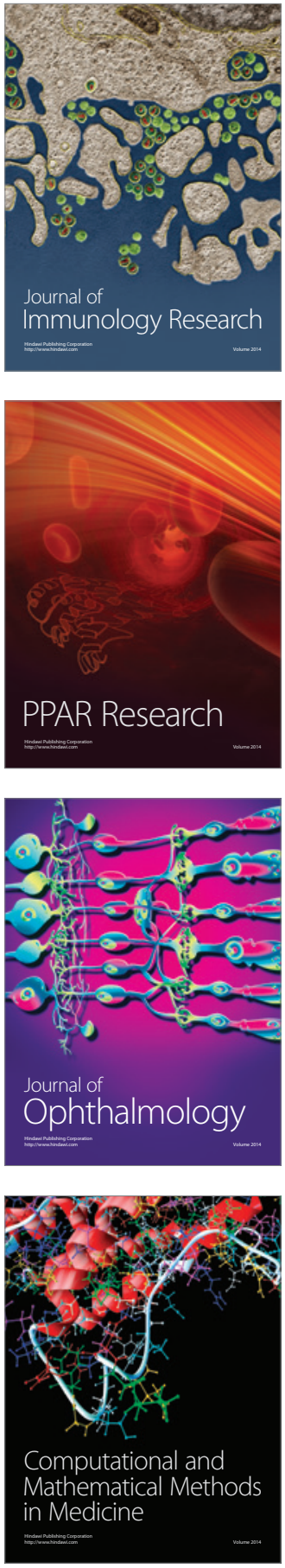

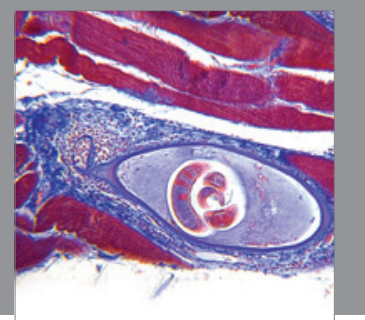

Gastroenterology

Research and Practice
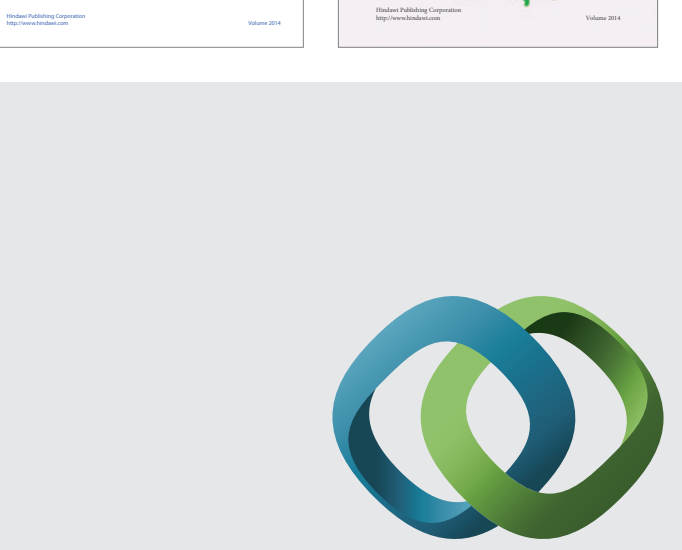

\section{Hindawi}

Submit your manuscripts at

http://www.hindawi.com
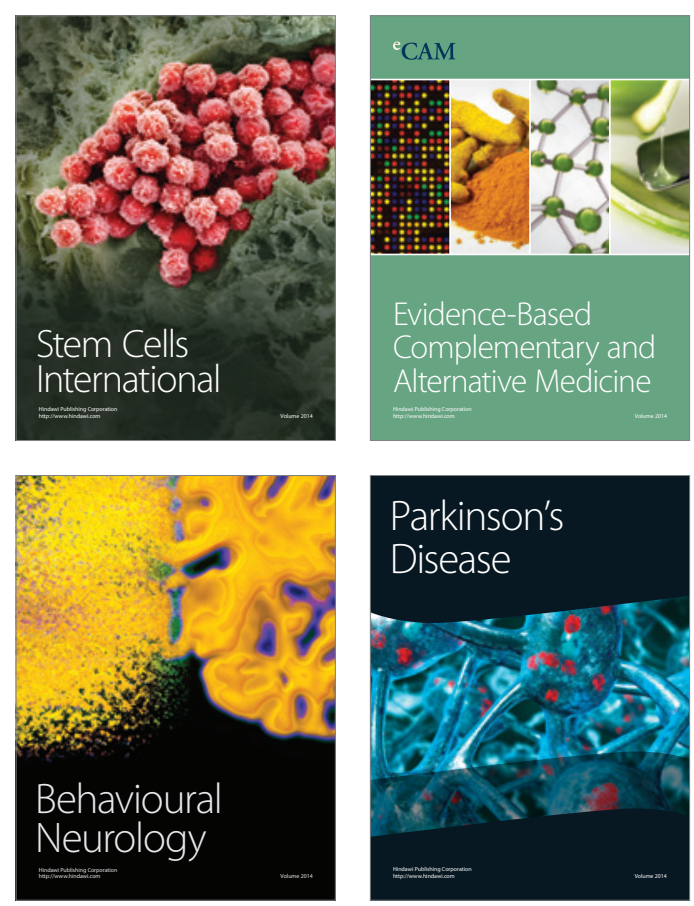

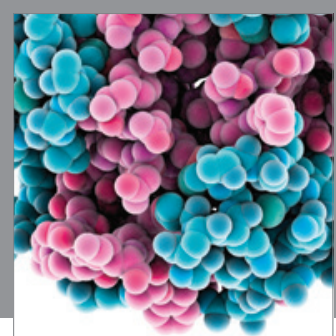

Journal of
Diabetes Research

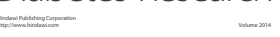

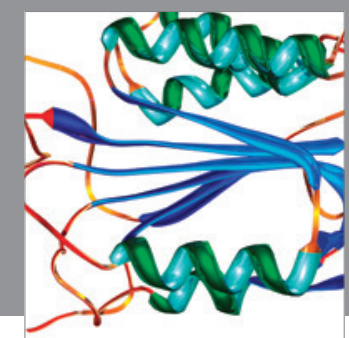

Disease Markers
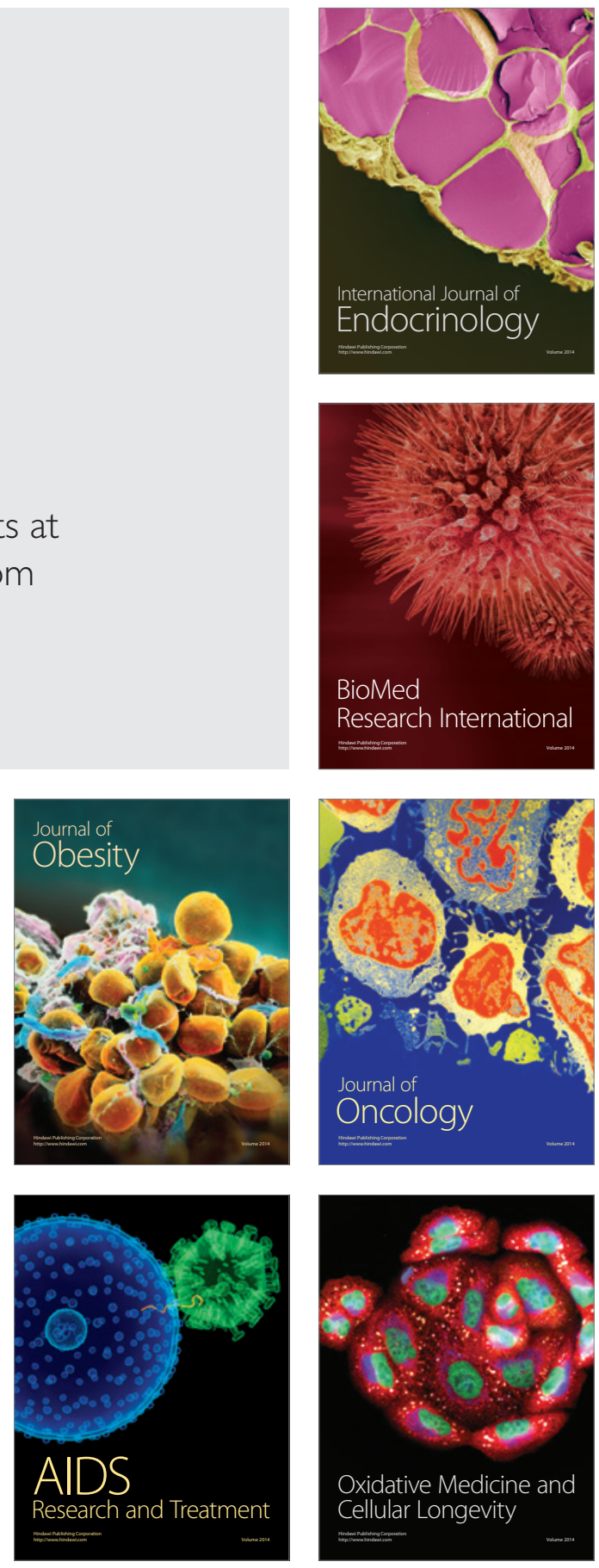